\title{
THE ROLE OF CD40 LIGAND IN EARLY DETECTION OF CHROMIUM-INDUCED IMMUNOTOXIC EFFECTS AMONG EXPOSED WORKERS
}

\author{
By \\ Gaballah I.F. and Zawilla N.H. and Rashed L.A.* \\ FROM \\ Department of Occupational Medicine and Environmental Diseases, \\ Faculty of Medicine, Cairo University \\ *Department of Biochemistry, Faculty of Medicine, Cairo University
}

\begin{abstract}
Objective: the immunological effect of chromium exposure among workers in tanning industry was assessed by studying the incidence of structural chromosomal aberrations in lymphocytes. Early monitoring of immunotoxicity and possibility of carcinogenecity using the CD40 ligand member of the tumor necrosis superfamily of trans-membrane proteins was evaluated.

Methods: levels of chromium in blood (S-Cr) and urine (U-Cr) were measured using the graphite furnace atomic absorption spectrophotometer. The CD40 Ligand (CD40L) was determined using ELISA. Whole blood was treated and chosen metaphases were recorded and scored for morphological aberrations and rearrangements.

Results: the study was carried out on 30 workers exposed to chromium in chrome-tanning for $17.13 \pm 8.09$ years, and a matched group of 28 administrative workers. The mean serum chromium levels $(\mathrm{S}-\mathrm{Cr})$ were $4.35 \pm 1.46$ and $1.89 \pm 1.31$ $\mu \mathrm{g} / \mathrm{dl}$ among exposed and control groups, respectively, and the difference was statistically significant, $\mathrm{P}<0.00 \pm$. The CD40L assessment revealed decreased levels among the exposed population, difference was statistically non-significant. The genotoxic changes in the form of chromosomal and chromatid gaps and breaks as well as dicen-
\end{abstract}


tric changes were significantly higher among exposed workers, correlating significantly with the levels of chromium in both serum and urine after correction for creatinine. A significant negative correlation was reported for the deletions with the level of CD40 ligand. The effect of age, smoking and cumulative exposure indices were dealt with.

Conclusion: the use of cytogenetic monitoring of human populations exposed to chemicals has proved to be a useful tool for detecting the chemical's mutagenic effects. CD40L, which is a member of the tumor necrosis factor, may be used as an additional marker to assess the presence of chronic inflammation, an early warning indication of potentially adverse genetic and somatic effects.

Key words: chromosomal aberrations, Ligands, chronic inflammation, chromium, tanning industry, carcinogenesis.

\section{Introduction}

Public concern has mounted recently about environmental exposures to chromium in soil, tap water, and ambient air. In response, agencies charged with protecting public health have attempted to study exposure by monitoring chromium levels among potentially exposed populations. The clinical significance of elevated chromium levels is not indicative of a significant health concern ${ }^{[1]}$. Being an excellent tanning agent, chromium $(\mathrm{Cr})$ is widely used in the leather industry. In the process of leather production, tannery workers are exposed to either inorganic compounds or $\mathrm{Cr}$ bound to proteins (leather dust). Absorption of chromium following inhalation is influenced by many factors including the particle size, oxidation state, solubility of the chromium particles, the activity of alveolar macrophages, and the interaction of chromium with biomolecules in the lungs following deposition ${ }^{[2]}$.

The hexavalent chromium (Cr-VI) enters the cells via diffusion through nonspecific anion channels while the trivalent compound (Cr-III) is less well absorbed due to the relative inability to cross cell membranes ${ }^{[3]}$. In the airways epithelial lining, significant reduction of $\mathrm{Cr}$-VI to Cr-III takes place by glutathione ${ }^{[4]}$. The chromic acid (Cr-III) formed is known to be irritating to the endothelial lining of the respiratory tract, it is likely that this chemical can act alone or with infection and cigarette smoking causing chronic inflammation ${ }^{[2]}$.

Recruitment and activation of circulating leukocytes at sites of inflammation are essential to clearance of infectious organisms and repair of tissue injury. Once acti- 
vated, infiltrating leukocytes generate a plethora of inflammatory mediators important in host defense [5]. These proinflammatory mediators up-regulate the expression of some adhesion molecules. CD40 Ligand (CD40L), also known as CD154 or gp39, is a trans-membrane protein expressed on T-cells, B-cells, mast cells, basophils, eosinophils, natural killer cells, macrophages, endothelial cells, vascular smooth muscle cells, activated platelets and is also found in plasma as a soluble protein, $\mathrm{SCD} 40 \mathrm{~L}^{[6]}$.

Recent studies indicated the initiation of several inflammatory processes as a consequence of CD40 Ligand (CD40L) binding to its receptor CD40 ${ }^{[7]}$. However, failure to clear the original stimulus and resolve the inflammatory response results in persistent release of these mediators, including cytokines, enzymes, eicosanoids, and reactive nitrogen and oxygen intermediates ${ }^{[5]}$.

There is evidence for the role of reactive oxygen species and oxidative DNA damage in the development of genotoxicity in the foci of inflammation ${ }^{[8]}$. Therefore, genetic lesions, such as chromosomal aberrations, amplification of oncogenes, and mutations of genes involved in the cell cycle regulation, must be essential for the growth of malignant tumor. Accordingly, the concept of malignancy developing in chronic inflammation was proposed [9]. CD40L which is considered a member of the tumor necrosis factor and nerve growth factor receptor family, was suggested to be over-expressed in a broad range of carcinomas, thus contributing to their development ${ }^{[7]}$.

Recently, chromium compounds were reported to be oxidizing genotoxic carcinogens associated with increased risk of respiratory tract cancers following occupational exposure ${ }^{[8]}$. However, how the inflammation promotes the accumulation of genetic lesions and induces the growth of cancerous cells remains unclear and the precise mechanisms remain to be elucidated.

\section{Aim of the Work}

This study was designed to investigate the immunological effects of chromium among a group of workers exposed in the tanning industry by studying the incidence of chromosomal aberrations in lymphocytes. Further, the role of the transmembrane CD40 ligand as a new non-invasive tool useful in the early detection of mutagenic changes was evaluated in an attempt to assess the role of chronic inflammation in the development of chromium-induced carcinogenesis. 


\section{Subjects and Methods}

\section{Study Population:}

Men exposed to chromium for at least 1 year in a contaminated area of the tanneries under study were eligible for inclusion. A randomized sample of 30 subjects was selected fulfilling the inclusion criteria constituted the target population. Referents were recruited among men employed in administration by a company situated away from tanneries and who have never been exposed to leather tanning or were living close to tanneries. The referents were matched with the exposed workers by age, sex, socioeconomic standards and consumption of smoking tobacco. For the study population, exclusion criteria included fever in the last six months, neoplasm, and concurrent opportunistic infection. All subjects underwent an interview emphasizing socio-demographic background, medical and occupational histories. The study population was then offered a voluntary medical examination after obtaining their approval.

\section{CD40 Assessment}

Baseline plasma sCD40L concentrations were measured by ELISA (Bender MedSystems). Diluted 1:5 plasma samples were applied in triplicate to 96-well plates precoated with mouse anti-human CD40L antibody and mixed (1:2) with a horserad- ish-peroxidase-labeled secondary mouse anti-human CD40L antibody (2 hours). Subsequently, plates were washed and antibody binding determined by colorimetry using 3,3'-5,5'-tetramethylbenzidine substrate. Absorbance was read at $650 \mathrm{~nm}$ and plasma concentrations of sCD40L were determined by comparison with serial dilutions of recombinant human CD40L. Analysis was performed in a blinded fashion. Intra-assay variation among the triplicates for all samples was less than $15 \%{ }^{[10]}$.

\section{Laboratory Measurements:}

A first morning urine sample from the day of the examination was collected and stored $\left(\right.$ at $\left.30^{\circ} \mathrm{C}\right)$ in a urine container $(25 \mathrm{ml})$. Blood specimens were obtained from the cubital vein. Heparinized wholeblood samples for measurements of kidney functions and liver functions and determination of chromium were collected and stored in $10 \mathrm{ml}$ tubes at $-20^{\circ} \mathrm{C}$. The samples used for assessing chromium level in blood (S-CrVI) were prepared by dilution of $0.5 \mathrm{ml}$ of blood with $2 \mathrm{ml}$ of deionized water. The urine samples were prepared by diluting $1 \mathrm{ml}$ of urine with $1 \mathrm{ml}$ of deionized water. Chromium in both blood and urine was measured by graphite furnace atomic absorption spectrophotometer (Perkin-Elmer model 5100PC, Norwalk, CT). The concentration of urinary chromium (U-CrVI) at the time of examination was 
used as an index of current exposure. The results of urinary chromium were then corrected for urinary creatinine. A cumulative index of exposure would have been a more reliable index of exposure, being based on the worker's mean U-Cr for each quarter of the year, unfortunately, no proper recording of previous results was available.

\section{Cytogenetic Analysis}

Whole blood $(0.5 \mathrm{ml})$ was added to $4.5 \mathrm{ml}$ of culture medium (RPMI $1640 \mathrm{Gib}-$ co) supplemented with L-glutamine. After incubation at 37!C for 72 hours, colchicine was added at a conc. $0.1 \mathrm{ml}$. The cultures were centrifuged for $10 \mathrm{~min}$. The supernatant fluid removed underwent hypotonic treatment with $0.075 \mathrm{ml} \mathrm{mol} \mathrm{Kcl} / \mathrm{L}$ for $30 \mathrm{~min}$ at $37: \mathrm{C}$. Fixation was finally done with 1:3 mixture of glacial acetic acid and methanol. The slides were left to dry after washing then stained for $5 \mathrm{~min}$. with $10 \%$ Giemsa solution in $\mathrm{pH} 6.8^{[11]}$.

\section{Chromosomal Aberration Analysis}

For analysis, 30 well-spread chosen metaphases were counted and scored for chromosome changes by direct observation at $X 1,250$. Observed aberrant cells were recorded and scored for morphological and numerical aberrations. The chromosomal aberrations were classified as structural aberrations such as chromatid gap $\left(G^{\prime}\right)$, isochromatid gap $\left(G^{\prime \prime}\right)$, chromat- id break (B'), isochromatid break (B"), dicentric (Dic), separation (Sep) and numerical aberrations such as deletion (Del).

\section{Statistical analysis}

The mean and standard deviation (SD) were calculated. Unpaired student's t-test was used to evaluate the relation between the different indices and compare the two study groups. Pearson correlation coefficient was used to relate between age, duration of exposure, cumulative exposure, smoking index, levels of chromium in blood (S-Cr) and in urine (U-Cr), creatinine-corrected urinary chromium level (creat-U-Cr), CD40L and the different chromosomal aberrations. A $\mathrm{P}$ value of $<$ 0.05 was considered significant.

\section{Results}

The study population consisted of 58 males randomly selected according to Monte Carlo System from a population of 250 worker at El-Obour District. The exposed group consisted of 30 workers exposed to chromium in tanneries while the control group was a group of 28 workers involved in carrying, driving, cleaning and food preparing activities. The age range of individuals in the exposed group was 24 to 59 years with a mean value of $40.17 \pm$ 10.97 years showing no statistically significant difference when compared with the control group (range $=20$ - 57 years; mean 
$=37.13 \pm 10.05$ years). As for the sex, smoking habits and socioeconomic standards, both exposed and control groups were selected so as to match each other. Current smoking was more prevalent in the exposed workers but, overall, the referents were comparable with the exposed subjects with no significant difference. As for the exposed population, the duration of chromium exposure in the tanning industry was $17.13 \pm 8.09$ years. Estimating the mean of cumulative exposure index (CMI), based on work history including working hours per day and duration in years, was found to be $154.9 \pm 71.35$ hour.

As regards the symptomatologic data among the study population, data not presented, the percentage of workers suffering from chemical irritation was $22(73.3 \%)$ among exposed workers and 12 (42.9\%) among control groups. A total of 17 $(56.7 \%)$ exposed and $8(28.6 \%)$ control subject had manifestations of pulmonary sensitization progressing into asthmatic attacks.

Evaluation of the liver and kidney functions was done to assess the effect of chromium exposure on these organs. Among the liver functions, bilirubin, serum glutamic-oxaloacetic transaminase (SGOT) and glutamic-pyruvic transaminase (SGPT) and gamma glutamyl transferase (GGT) enzymes showed no statistical difference between the exposed $(n=30)$ and control $(n=28)$ groups. Two control subjects, having active hepatitis with 5 times elevation in liver enzymes were excluded.

Kidney functions revealed statistically significant difference between the exposed and control group for urea $(\mathrm{P}<0.05)$, but not for creatinine level. Measured urinary chromium level in exposed population ranged from 1.06 to $5.31 \mu \mathrm{g} / \mathrm{dl}$ with a mean value of $2.98 \pm 1.44 \mu \mathrm{g} / \mathrm{dl}$. As for the control group, urinary chromium level ranged from 0.1 to $2.5 \mu \mathrm{g} / \mathrm{dl}$ with a mean value of $0.94 \pm 0.39 \mu \mathrm{g} / \mathrm{dl}$. Correction for urinary creatinine was done for the chromium level. Creatinine-corrected urinary chromium level among the exposed population ranged from 0.49 to $5.84 \mu \mathrm{g} / \mathrm{mg}$ creatinine in urine. The mean value was $2.47 \pm 1.25 \mu \mathrm{g} / \mathrm{mg}$ Creat. The difference between chromium-exposed subjects and the control group (mean $0.62 \pm 0.55 \mu \mathrm{g}$ / $\mathrm{mg}$ Creat) proved to be highly significant $(\mathrm{P}<0.001)($ Table 1).

Estimation of the blood level of chromium showed a highly statistically significant difference with mean values of $4.35 \pm$ 1.46 and $1.89 \pm 1.31 \mu \mathrm{g} / \mathrm{dl}$ among exposed and control groups, respectively $(\mathrm{P}<0.001)$. The exposed workers had statistically significant high concentrations of $\mathrm{Cr}$ in urine than the referents. Serum 
CD40 Ligand (sCD40L) assessment revealed a difference between both groups. The mean values were $2.04 \pm 2.18 \mathrm{ng} / \mathrm{ml}$ for the exposed group and $2.69 \pm 1.12 \mathrm{ng} /$ $\mathrm{ml}$ for the control group, the difference proved to be statistically non-significant (Table 1).

Evaluating the level of chromosomal aberrations in both the exposed and control groups revealed structural changes but no numerical abnormalities. The structural aberrations obtained in the form of gaps, isochromatid gaps, breaks, isochromatid breaks and separation were all found to be more than double among the exposed group in comparison to the control group. The difference in the levels between both groups was found to be highly significant statistically. As for deletion and dicentric changes, the level was higher among the control than exposed group, the difference being statistically significant (Table 2).

Assessment of the relationships between the different variables in the study revealed a positive correlation between the effect of age and smoking index (SI) versus the serum chromium ( $\mathrm{S}-\mathrm{Cr}$ ) and creatinine-corrected urinary chromium level (creat-U-Cr) and a negative correlation versus the sCD40 Ligand among the study population $(\mathrm{n}=58)$. All correlations were statistically insignificant. Similarly a nonsignificant correlation was obtained for the
CMI and studied parameters among the exposed group of workers at the tanneries. The sCD40L was also non-significantly correlated to the levels of chromium in serum and in urine. However, a highly significant correlation was found between the serum chromium level and the level of chromium in urine after correction for creatinine (Table 3).

The chromosomal aberrations examined in the study were studied in relation to each individual's age, smoking index and duration of exposure at work. However, no statistical significant correlation was obtained except for the correlation between the CMI and number of chromosomal gaps $(r=0.427 ; P<0.05)$. As for the serum and urinary chromium levels, highly significant positive correlation was obtained for the chromosomal aberrations in the form of gaps, breaks, iso-chromatid gaps and iso-chromatid breaks. As for the negative association detected for the dicentric changes, it proved to be highly significant with the S-Cr and significant with the creat-U-Cr. However, a non-significant correlation was obtained for deletion and separation. The associations of chromosomal changes with the sCD40L revealed negative correlation with the different types of chromosomal aberrations that proved to be highly significant for deletion (Table 4). 
Table (1): Mean \pm SD of the ressults of Different Laboratory Investigations among the Exposed Group of Workers in Tanning $(n=30)$ and the Non-exposed Control Group ( $\mathrm{n}=28)$.

\begin{tabular}{|l|c|c|c|c|c|}
\hline & & $\begin{array}{c}\text { Exposed Group } \\
\mathrm{n}=30\end{array}$ & $\begin{array}{c}\text { Control Group } \\
\mathrm{n}=28\end{array}$ & t-test & P value \\
\hline \multirow{3}{*}{$\mathrm{S}-\mathrm{Cr}$} & Range & $2.01-6.23$ & $0.2-5.1$ & & \\
& Mean & 4.348 & 1.889 & 6.858 & $0.000^{*}$ \\
& SD & 1.458 & 1.314 & & \\
\hline \multirow{3}{*}{ U-Cr } & Range & $1.06-5.31$ & $0.1-2.5$ & & \\
& Mean & 2.978 & 0.941 & 7.493 & $0.000^{*}$ \\
& SD & 1.438 & 0.389 & & \\
\hline \multirow{3}{*}{ sCreat } & Range & $0.4-1.2$ & $0.5-1.2$ & & \\
& Mean & 0.763 & 0.741 & 0.253 & N.S. \\
& SD & 0.401 & 0.308 & & \\
\hline \multirow{3}{*}{ creat-U-Cr } & Range & $0.49-5.84$ & $0.04-1.81$ & & \\
& Mean & 2.467 & 0.622 & 6.034 & $0.000^{*}$ \\
& SD & 1.249 & 0.548 & & \\
\hline \multirow{3}{*}{ sCD40L } & Range & $0.01-7.6$ & $0.2-2.9$ & & \\
& Mean & 2.041 & 2.691 & 1.451 & N.S. \\
& SD & 2.183 & 1.116 & & \\
\hline
\end{tabular}

$S$-Cr: Level of Chromium in Serum ( $\mu g / d l) ; U$-Cr Level of Chromium in Urine ( $\mu g / d l)$;

SCreat: Serum Creatinine ( $g$ );

creat-U-Cr: Creatinine-corrected Urinary Chromium Level ( $\mu g / g$ creatinine in urine);

sCD4OL: serum CD40 Ligand $(\mathrm{ng} / \mathrm{ml})$

*Highly Significant $P<0.005$ 
Table (2): Mean \pm SD of the results of Different Chromosomal Aberrations among the Exposed Group of Workers in Tanning $(\mathrm{n}=30)$ and the Non-exposed Control Group $(n=28)$.

\begin{tabular}{|c|c|c|c|c|c|}
\hline & & $\begin{array}{c}\text { Exposed Group } \\
\mathrm{n}=30\end{array}$ & $\begin{array}{c}\text { Control Group } \\
\qquad \mathrm{n}=28\end{array}$ & t-test & $P$ value \\
\hline Gap & $\begin{array}{c}\text { Range } \\
\text { Mean } \\
\text { SD }\end{array}$ & $\begin{array}{c}3-10 \\
6.13 \\
1.961\end{array}$ & $\begin{array}{c}0-4 \\
1.60 \\
0.932\end{array}$ & 11.438 & $0.000 *$ \\
\hline Break & $\begin{array}{c}\text { Range } \\
\text { Mean } \\
\text { SD }\end{array}$ & $\begin{array}{c}0-10 \\
5.70 \\
2.215\end{array}$ & $\begin{array}{c}0-2 \\
0.70 \\
0.651\end{array}$ & 11.861 & $0.000 *$ \\
\hline IsoGap & $\begin{array}{c}\text { Range } \\
\text { Mean } \\
\text { SD }\end{array}$ & $\begin{array}{l}0-6 \\
2.23 \\
1.431\end{array}$ & $\begin{array}{c}0-3 \\
0.30 \\
0.466\end{array}$ & 7.037 & $0.000 *$ \\
\hline IsoBreak & $\begin{array}{c}\text { Range } \\
\text { Mean } \\
\text { SD }\end{array}$ & $\begin{array}{c}0-4 \\
1.67 \\
1.213\end{array}$ & $\begin{array}{c}0-1 \\
1.10 \\
0.305\end{array}$ & 6.861 & $0.000 *$ \\
\hline Deletion & $\begin{array}{c}\text { Range } \\
\text { Mean } \\
\text { SD }\end{array}$ & $\begin{array}{c}0-4 \\
0.93 \\
0.201\end{array}$ & $\begin{array}{c}0-1 \\
1.081 \\
0.407\end{array}$ & 3.479 & $0.001 *$ \\
\hline Dicentric & $\begin{array}{c}\text { Range } \\
\text { Mean } \\
\text { SD }\end{array}$ & $\begin{array}{c}0-4 \\
1.25 \\
0.102\end{array}$ & $\begin{array}{c}0-1 \\
1.291 \\
0.305\end{array}$ & 4.682 & $0.000 *$ \\
\hline Separation & $\begin{array}{c}\text { Range } \\
\text { Mean } \\
\text { SD }\end{array}$ & $\begin{array}{c}0-2 \\
0.90 \\
0.568\end{array}$ & $\begin{array}{c}0-1 \\
0.20 \\
0.407\end{array}$ & 4.259 & $0.000 *$ \\
\hline
\end{tabular}


Table (3): Correlation Coefficient (r) of the Level of Chromium in Serum (S-Cr), Creatinine-corrected Urinary Chromium Level (creat-U-Cr) and CD40L versus $\mathrm{Cu}$ mulative Exposure Index (CMI) among the Exposed Population $(n=30)$ and versus Age, Smoking Index (SI), S-Cr, creat-U-Cr and sCD40L among the Studied Population $(\mathrm{n}=58)$.

\begin{tabular}{|l|c|c|c|c|c|c|c|}
\hline & & $\begin{array}{c}\text { CMI } \\
\mathrm{n}=30\end{array}$ & $\begin{array}{c}\text { Age } \\
\mathrm{n}=58\end{array}$ & $\begin{array}{c}\text { SI } \\
\mathrm{n}=58\end{array}$ & $\begin{array}{c}\text { S-Cr } \\
\mathrm{N}=58\end{array}$ & $\begin{array}{c}\text { creat-U-Cr } \\
\mathrm{n}=58\end{array}$ & $\begin{array}{c}\text { sCD40L } \\
\mathrm{n}=58\end{array}$ \\
\hline S-Cr & r value & -0.068 & 0.098 & 0.049 & --- & 0.625 & 0.121 \\
& P value & 0.721 & 0.464 & 0.714 & --- & $0.000 * *$ & 0.365 \\
\hline creat-U-Cr & r value & 0.123 & 0.116 & 0.064 & 0.625 & --- & 0.060 \\
& P value & 0.357 & 0.386 & 0.632 & $0.000 * *$ & --- & 0.654 \\
\hline \multirow{2}{*}{ SCD40L } & r value & -0.175 & -0.146 & -0.159 & 0.121 & 0.060 & --- \\
& P value & 0.355 & 0.274 & 0.231 & 0.365 & 0.654 & --- \\
\hline
\end{tabular}

CMI: cumulative exposure index (hours.year); SI: smoking index (pack.year)

$S$-Cr: Level of Chromium in Serum $(\mu g / d l)$;

creat-U-Cr: Creatinine-corrected Urinary Chromium Level ( $\mu g / g$ creatinine in urine);

sCD4OL: serum CD4O Ligand ( $\mathrm{ng} / \mathrm{ml})$

*Highly Significant $P<0.005$

**Highly Significant $P<0.005$ 
Table (4): Correlation Coefficient (r) of the Chromosomal Aberrations versus Cumulative Exposure Index (CMI) among the Exposed Population $(n=30)$ and versus Age, Smoking Index (SI), S-Cr, creat-U-Cr and sCD40L among the Studied Population $(n=58)$.

\begin{tabular}{|c|c|c|c|c|c|c|c|}
\hline & & $\begin{array}{l}\text { CMI } \\
n=30\end{array}$ & $\begin{array}{l}\text { Age } \\
\mathrm{n}=58\end{array}$ & $\begin{array}{c}\text { SI } \\
\mathrm{n}=58\end{array}$ & $\begin{array}{l}\mathrm{S}-\mathrm{Cr} \\
\mathrm{N}=58\end{array}$ & $\begin{array}{c}\text { creat-U-Cr } \\
\mathrm{n}=58\end{array}$ & $\begin{array}{c}\text { sCD40L } \\
n=58\end{array}$ \\
\hline \multirow[t]{2}{*}{ Gap } & $\mathrm{r}$ value & 0.427 & 0.209 & 0.047 & 0.546 & 0.642 & -0.224 \\
\hline & $P$ value & $0.019 *$ & 0.115 & 0.726 & $0.000 * *$ & $0.000 * *$ & 0.091 \\
\hline \multirow[t]{2}{*}{ Break } & $\mathrm{r}$ value & -0.207 & 0.073 & -0.168 & 0.508 & 0.493 & -0.209 \\
\hline & $P$ value & 0.272 & 0.586 & 0.208 & $0.000 * *$ & $0.000 * *$ & 0.115 \\
\hline \multirow[t]{2}{*}{ IsoGap } & $\mathrm{r}$ value & -0.152 & -0.103 & -0.119 & 0.483 & 0.424 & -0.198 \\
\hline & $P$ value & 0.423 & 0.442 & 0.374 & $0.000 * *$ & $0.000 * *$ & 0.136 \\
\hline \multirow[t]{2}{*}{ IsoBreak } & $\mathrm{r}$ value & -0.150 & -0.039 & -0.057 & 0.524 & 0.354 & -0.023 \\
\hline & $P$ value & 0.429 & 0.771 & 0.671 & $0.000 * *$ & $0.006 * *$ & 0.864 \\
\hline \multirow[t]{2}{*}{ Deletion } & $r$ value & -0.109 & 0.117 & -0.109 & 0.067 & 0.247 & -0.361 \\
\hline & $P$ value & 0.566 & 0.382 & 0.415 & 0.617 & 0.062 & $0.005 * *$ \\
\hline \multirow[t]{2}{*}{ Dicentric } & r value & -0.196 & -0.071 & -0.255 & -0.695 & -0.311 & -0.019 \\
\hline & $P$ value & 0.299 & 0.596 & 0.053 & $0.000 * *$ & $0.018 *$ & 0.887 \\
\hline \multirow[t]{2}{*}{ Separation } & $\mathrm{r}$ value & 0.004 & 0.178 & -0.155 & -0.037 & -0.005 & -0.225 \\
\hline & $P$ value & 0.983 & 0.181 & 0.245 & 0.783 & 0.969 & 0.089 \\
\hline
\end{tabular}

CMI: cumulative exposure index (hours.year); SI: smoking index (pack.year)

$S$-Cr: Level of Chromium in Serum $(\mu g / d l)$;

creat-U-Cr: Creatinine-corrected Urinary Chromium Level ( $\mu g / g$ creatinine in urine);

sCD4OL: serum CD4O Ligand $(\mathrm{ng} / \mathrm{ml})$

*Highly Significant $P<0.005$

**Highly Significant $P<0.005$ 


\section{Discussion}

Numerous environmental agents can increase the probability of somatic mutation that plays a critical role in carcinogenesis ${ }^{[12]}$. Chromium which has been used commercially for more than 100 years in metal alloys and other compounds, as a pigment, and in the tanning and metal plating industries, is one of these inhalant carcinogenic agents ${ }^{[13]}$.

Airway epithelial cells, which represent the first barrier to aeroallergens, form a continuous pseudostratified layer in the lung that protects underlying tissue from the external environment. However, their active role in the inflammatory response has never been investigated in-depth. Recent studies suggest that airway epithelial cells interact with immune effector cells in response to noxious stimuli by the expression of surface molecules involved in the adhesion and activation of recruited leukocytes and by the release of certain mediators ${ }^{[14]}$.

In the initial phase of inflammatory response, circulating leukocytes are activated by exposure to inflammatory mediators including complement fragments (C5a), cytokines such as IL-1, IL-8 and tumor necrosis factors. The CD40 Ligand (CD40L), a member of the tumor necrosis factor receptor family, leads to their microvascular sequestration due, in part, to increased cell stiffness and, in part, to increased adhesiveness of the circulating leukocytes ${ }^{[15]}$. Airway epithelial cells, highly susceptible to these mediators, are similarly activated resulting in enhanced expression of several adhesion molecules. The interaction between the CD40L-positive lymphocyte and its counter-receptor CD40 overexpressed on the airway epithelial cells plays a key role in several inflammatory processes. This network of interactions, which includes immune-competent and resident cells, results in a self-maintaining inflammatory loop, which could at least in part explain the frequent association between allergy and loco-regional inflammation ${ }^{[14] \text {. }}$

However, failure to clear the original stimulus and resolve the inflammatory response results in persistent release of mediators and over-expression of the CD40L facilitating the release of large quantities of toxic oxygen radicals and proteolytic enzymes. As a consequence of enhanced lipid peroxidation, the resulting DNA damage contributes to the development of a broad range of carcinoma ${ }^{[7]}$. In occupational exposure, following entry into the cytoplasm of airway epithelial cells, the trivalent chromium intermediates generated by spontaneous reduction of hexavalent 
chromium, avoid cytoplasmic chelation and migrate into the nucleus inducing the covalent interaction with DNA forming DNA-protein complexes. In addition, they generate short-lived redox oxygen radicals as a result of chromium-induced depletion of glutathione, thus producing reactive oxygen species (ROS) as superoxide ion, hydrogen peroxide and hydroxyl radical ${ }^{[16]}$. The ROS are known to be cytotoxic causing inflammatory disease including tissue necrosis, mutation and malignancy, a process that involves changes in the cellular adherence thus facilitating the disruption of normal tissue architecture ${ }^{[17]}$. Recent evidence supports the presence of clear links between chronic inflammation and cancer. Strong epidemiological and genetic evidence indicates that inflammation can drive tumour progression and that the disruption of endogenous antiinflammatory mechanisms can lead to tumour development ${ }^{[9]}$.

In this work, the two groups under study were properly matched as regards the age and smoking index indicating the absence of influence of these confounding factors on the results of the study. The mean cumulative exposure index to chromium in the tanning industry was $154.9 \pm$ 71.35 hours. A detailed analysis of cytogenetic activity induced by chromium com- pounds in a lymphocyte culture of exposed persons showed that the duration of contact and the level of exposure to chromium are dependent factors in the frequency of cells with chromosome aberrations ${ }^{[18] \text {. }}$

The tanning industrial processes consist of trimming, fleshing, unhairing of hides, followed by bating, pickling, chrome tanning and splitting of hides, and finally stacking, dry milling, buffing, spray finishing and plating ${ }^{[2]}$. As the tanneries included in the study were all smallsized, it was not possible to divide the exposures according to the industrial processes. All workers involved in the tanning process were exposed to chromium as evidenced by the increased levels of chromium in blood and urine.

In the blood stream, the oxidation form of chromium, namely trivalent chromium (Cr-III), is the determining factor in its transport. Whole body distribution studies indicate that the liver, kidneys, spleen and testes accumulate the majority of chromium after exposure, and to a lesser extent the heart, pancreas, lung and brain ${ }^{[19]}$. Many studies have looked at the chromium effects in terms of occupational health and that it could cause deleterious health effects including kidney and liver damage, though certain questions remain about which routes of exposures are dangerous for humans ${ }^{[13]}$. 
In the current study, no kidney affection was detected as determined by the creatinine levels. However, a significant difference was obtained between the exposed and control groups, though within normal levels. In a previous study of tannery workers whose duration of employment extended to 30 years, kidney functions were within normal limits, even though urinary chromium levels clearly indicated chromium exposure. A suggested urinary threshold for nephrotoxic effects was $25 \mu \mathrm{g} / \mathrm{g}$ creatinine ${ }^{[20,21]}$. In this study, the normal renal status might be related to the short duration of exposure (mean $17.13 \pm 8.09$ years) and low urinary creatinine-corrected chromium level not exceeding $5.84 \mu \mathrm{g} / \mathrm{g}$ creatinine. As for the liver affection, no abnormalities were detected as determined by the liver function tests. Consistent with these results, acute toxic effect of chromium on the liver has not been described ${ }^{[22]}$, and limited data indicate that chronic exposure to chromium compounds can cause hepatic effects [23].

Blood distribution of chromium appears to be divided evenly between plasma and erythrocytes. In the absence of known exposure, whole blood chromium concentrations are in the range of $2-3 \mu \mathrm{g} / \mathrm{dl}$, values above background levels are consid- ered potentially toxic ${ }^{[24]}$. The blood level of chromium ( $\mathrm{S}-\mathrm{Cr}$ ) in this study ranged from 2.01 to $6.23 \mu \mathrm{g} / \mathrm{dl}$, therefore exceeding the toxic levels mentioned in the literature.

Chromium rapidly clears from the blood and measurements relate only to acute exposure. Following clearance from the blood, chromium is excreted principally in the urine. Evidently, a positive highly significant correlation was obtained in this study between the level of $\mathrm{S}-\mathrm{Cr}$ and the chromium level in urine (U-Cr) indicating the recent exposure among the exposed population. Measurements of chromium in plasma were considered a more definitive gauge of environmental exposure than urinary biomonitoring ${ }^{[1]}$. But, recently, studies demonstrated the utility of urine samples in biological monitoring for assessment of occupational exposure to chromium ${ }^{[25]}$. Additionally, elevated concentration of chromium in blood and urine were significantly correlated with airborne metal concentration ${ }^{[26]}$. Normal urinary levels of chromium in humans, influenced by food, beverage intake, smoking and exercise ${ }^{[1]}$, have been reported to range from $0.24-1.8 \mu \mathrm{g} / \mathrm{dl}{ }^{[19]}$. In the exposed population of the current study, the $\mathrm{U}-\mathrm{Cr}$ level seemed to exceed normal limits showing a highly significant statistical dif- 
ference compared to the control group (mean $0.94 \pm 0.39 \mu \mathrm{g} / \mathrm{dl}$ ), $\mathrm{P}$ value $<0.005$. The mean values of U-Cr among the exposed population was $2.98 \pm 1.44 \mu \mathrm{g} / \mathrm{dl}$ corresponding to air levels of soluble chromium compounds of $33 \mu \mathrm{g} / \mathrm{m} 3$. In occupational settings, a urinary chromium concentration of $4 \mu \mathrm{g} / \mathrm{dl}$ to $5 \mu \mathrm{g} / \mathrm{dl}$ immediately after shift-work reflects exposure to air levels of $50 \mu \mathrm{g} / \mathrm{m} 3$ of soluble Cr-VI compounds, a concentration associated with nasal perforation ${ }^{[23]}$.

Exposure for several days to lower chromium concentrations of about 20 to $30 \mathrm{mg} / \mathrm{m} 3$ results in sneezing, rhinorrhea, cough, dyspnea and substernal pain ${ }^{[27]}$. Accordingly, frequency distribution of symptomatology in the current study showed more prevalence of sneezing, rhinorrhea, cough, dyspnea, substernal pain and to a lesser extent attacks of bronchospam among the exposed population. Consistently, other studies proved that chronic exposure to chromium results in the occurrence of upper and lower respiratory tract irritation as a result of chromium dust exposure ${ }^{[27]}$. Pulmonary sensitization in the form of asthmatic attacks was detected among the exposed population similar to the chromium-induced asthmatic responses elicited upon the inhalation challenge with nebulized potassium chromate ${ }^{[28]}$.
Exacerbations of allergy in the respiratory tract are related to locoregional inflammation, sustained by a combination of both cytokines and chemokines. These pro-inflammatory mediators up-regulate the expression of some adhesion molecules. The CD40L, a member of the TNF family, is also much more widely expressed than initially thought; its expression appears not to be restricted to the activated CD4+ T cells, but is also present on eosinophils, mast cells, and basophils ${ }^{[14]}$. Therefore, sCD40L assigns a central role in the inflammatory reaction in upper respiratory airway allergy ${ }^{[7]}$. In this work, estimating the levels of CD40L revealed lower levels among the exposed (mean $2.04 \pm 2.18 \mathrm{ng} / \mathrm{ml}$ ) than the control groups (mean $2.69 \pm 1.12 \mathrm{ng} / \mathrm{ml}$ ); the difference obtained was statistically non-significant. The CD40 molecule is barely detectable on resting cells, but is found in plasma of normal individuals as a soluble protein ${ }^{[6]}$. Lowered serum CD40L levels in our patients, mostly resulting from interaction between sCD40L and its counterreceptor CD40, should be attributed solely to chromium exposure because patients with other conditions causing immune system activation, such as fever, neoplasm, and concurrent opportunistic infection, were excluded from the study. The engagement 
of CD40 by CD40L has a principal role in the immune system, inducing differentiation, cell survival and proliferation ${ }^{[29]}$.

Though non-significant statistically, a negative correlation was obtained for sCD40L levels versus smoking and age. These data are strongly supported by many research studies providing a better understanding of immunomodulation induced by smoking and showing decrease in the concentration of adhesion molecules. These data suggest that the elevated concentration of serum soluble intercellular adhesion molecules (sICAM) in smokers, reported in earlier studies, are not due to an immediate effect of smoking [30]. As well, similar data related to age demonstrated that progressive decline of CD4+ T cells is followed by a decline in serum C40L levels, since CD40L is expressed mainly on CD4+ $\mathrm{T}$ cells ${ }^{[6]}$. The state of immunosenescence is therefore characterized by contraction of $\mathrm{T}$ cell receptor diversity ${ }^{[31]}$, and the progressive deterioration in the ability to respond to infections and to develop immunity ${ }^{[32]}$.

Though the level of sCD40L was lower among exposed than control groups, yet a positive correlation was obtained for both serum and urinary chromium levels. However, the correlation was statistically insignificant. This correlation suggests the continuous cleavage of the surface molecule expressed on activated cells to replace the normal T cell-derived CD40L signal to CD40-bearing cells ${ }^{[6]}$. The presence of association between SCD40L and chromium truly represent a first step in the development of mutagenesis. From pathoepidemiological studies, the concept of malignancy developing in chronic inflammation was proposed. For the autonomous growth of malignant tumor, genetic lesions, such as chromosomal aberrations, amplification of oncogenes, and mutations of genes involved in the cell cycle regulation, must be essential ${ }^{[5]}$. Chromium elicits these effects by covalent interaction with DNA in the form of DNA-protein cross-links ${ }^{[16]}$, and by the production of reactive oxygen species in the foci of inflammation, thus playing a role in mutagenesis and carcingenesis ${ }^{[33]}$.

Evaluating the level of chromosomal aberrations between both the exposed and control groups revealed structural changes but no numerical abnormalities. The structural chromosomal aberrations obtained in the form of gaps, isochromatid gaps, breaks, isochromatid breaks and separation were all found to be more than double among the exposed group in comparison to the control group. The difference in the levels between both groups was found to 
be highly significant statistically for all abnormalities except for deletion and the dicentric changes, where the difference was only significant. These data have been strongly supported by studies confirming that the target of ROS is DNA with possible strand breaks or mutation in addition to the alteration in transcription activities [34]. However, in another study, no significant difference was observed between exposed and controls workers exposed to chromium with regard to the frequency of peripheral lymphocytes with chromosome aberrations ${ }^{[35]}$. Nowadays, DNA-protein cross-links are considered a promising biomarker signaling an exposure of body tissues to biologically active forms of chromium ${ }^{[36]}$.

As regards age and smoking index, the results of studied correlation with the types of structural rearrangements of chromosomes were insignificant. An earlier statistical analysis of chromosomal aberrations revealed only a marginal impact of smoking habits whereas an agedependence has been established ${ }^{[37]}$. Increasing the rate of chromosomal aberrations with age has been observed in samples of studied individuals from newborns to 40-year-old persons. However, a decrease in the frequency of aberrations in older groups was observed as a result of gradual decrease of proliferative cell capacities ${ }^{[38]}$. As for smoking, a dose-effect relationship, shown by the increase in the frequency of chromosomal aberrations with an increase in the pack-years of consumption was reported in a recent study [39].

A significant association between the length of exposure (CMI) and extent of chromosomal gaps was revealed by the current results. Chromium was reported to be a genotoxic carcinogen affecting the fragile site, a heritable point on the chromosome where gaps and breaks tend to occur. The results obtained in this study might be strongly supported by the detectable increase in lymphocyte DNA damage due to chronic occupational exposure to Cr-III which correlated significantly with exposure of the cells to the metal ${ }^{[36]}$. Although the precise mechanisms remain to be elucidated, there is evidence for a role of oxidative DNA damage in the genotoxicity ${ }^{[8]}$.

The more the level of exposure as evidenced by both serum and urine chromium levels, the more the chromatid and chromosome gaps and breaks detected in the current study. This positive correlation proved to be highly significant, except for deletions and separation. As for the dicentric changes, a negative association proved 
highly significant for the S-Cr level and significant for U-Cr levels. Cytogenetic studies reported that dicentric yield decreases with time after exposure to noxious endogenous or exogenous agents. Dicentric chromosome, an abnormal chromosome with two centromeres rather than the normal one, is a reversible aberration that leads to transient chromosome instability ${ }^{[37]}$. The genetic integrity of a cell depends upon stable chromosomes where centromeres play an essential role in cell division ${ }^{[11]}$.

Consistent with these results, a recent study assessing the effects of S-Cr concentration on chromosomal integrity revealed a statistical correlation with both the frequency of chromatid exchange and the total frequency of chromosome and chromatid breaks and exchanges. Accordingly, the genotoxicity in Cr-exposed workers was consequential at quite low exposure levels, plus chromosome rearrangement was clearly evident as a biological response marker for $\mathrm{Cr}$ exposure based on a significant positive correlation between the chromosomal aberrations and the $\mathrm{Cr}$ in the blood $^{[40]}$.

In fact, chromosomal aberrations and mutations of genes are involved in the cell cycle regulation and have an important role in the initial steps of tumorigenesis
[7]. Tumorigenesis is a process that involves cell adhesion molecules. Additionally, there must be changes in the cellular adherence which facilitate the disruption of normal tissue architecture ${ }^{[15]}$. Studying the association of the CD40L and the chromosomal aberrations revealed a negative correlation for the different types of chromosomal aberrations. In fact, decreased serum levels of CD40L as a consequence of CD40L binding to its over-expressed receptor CD40, correlated significantly with increased chromosomal aberrations in the form of deletions where lost segments occur as a result of chromium-induced structural changes. These data possibly indicate the initiation of several inflammatory processes and the subsequent mutagenesis as a result of occupational exposure. DNA double-strand breaks are among the most deleterious types of damage that can occur in the genome because failure to repair them can lead to loss of genetic information and chromosome rearrangements. They arise by failures in DNA replication and by exposure to environmental factors [41]. Recent study confirms the previously reported association between level of chromosomal aberrations and cancer risk ${ }^{[42]}$.

In conclusion, scoring for structural chromosome abnormalities is one of the only practical methods available for de- 
tecting structural damage in an occupational setting. Cytogenetic tests have shown the clastogenic potential of a number of metals and metal compounds, in spite of the difficulties in identifying a specific clastogen, where simultaneous exposure to a number of organic and inorganic chemicals is a common phenomenon. Metals, known to be carcinogens, tend to possess chromosome-damaging properties, even though more extensive studies are still needed before any conclusive evidence can be reached. Study of the expression of the molecules on the surface of various cells or of the soluble form in the plasma may provide insights into their roles in pathophysiology in neoplastic diseases. Additionally, differences in levels of soluble cell adhesion molecules in the plasma may be useful tools in stratifying disease severity or prognosis. Therefore, soluble adhesion molecules might be considered as risk markers of a wide range of human environmental and occupational exposures, whereas specific adhesion of molecules may play a direct role in pathological processes. The CD40L over-expression on the surface of airway epithelial cells induced by chromium exposure, though nonspecifically, is suggested to be a tool in the detection of the initiation of chronic inflammation. Lowered sCD40L may be a proposed additional marker to assess the possibility of the development of carcinogenesis. Yet, further investigation and larger scale studies are needed, as adhesion molecules constitute one of the fastest growing and most confusing topics in the body's local immune response.

\section{Recommendations}

Accordingly, serum CD40L estimation is recommended during the preemployment examination to exclude those with chronic inflammation or immune system activation. The CD40L levels may then be utilized periodically as early indicator of chronic inflammation. Periodic creatinine-corrected urinary chromium estimation, every 3 or 6 months, is needed for recording the cumulative exposure of exposed workers so as to exclude those exceeding $4 \mu \mathrm{g} / \mathrm{g}$ creatinine, which is the level at risk of nasal perforation. The use of genotoxicity testing is essential for assessing potential human toxicity so that the hazards can be prevented. Keeping selenium at higher level among the occupationally exposed workers, through daily intake of selenium-rich diet, or Se supplements, undoubtedly is important to guard against chromium toxicity as a result of oxidative stress. Besides, implementation of cleaner production processes and pollution preven- 
tion measures can yield environmental benefits. Reduction in chromium pollution can be achieved through measures to increase the levels of chrome that are fixed in the tanning bath and reduce the amounts that are "bled out" in subsequent processes. Other methods to reduce release of chromium are through direct recycling by treatment and precipitation of chromium as hydroxide. Other tanning agents such as titanium used as substitutes for chromium to produce salts of generally lower toxicity and safer to handle, should be considered.

\section{References}

1. Paustenbach D.J., Panko J.M., Fredrick M.M., Finley B.L. and Proctor D.M. (1997): Urinary chromium as a biological marker of environmental exposure: what are the limitations? Regul. Toxicol. Pharmacol. 26(1 Pt 2):S23-34.

2. Stupar J., Vrtovec M., Kocijancic A. and Gantar A. (1999): Chromium status of tannery workers in relation to metabolic disorders. J. Appl. Toxicol. 19(6):437-46.

3. Anderson R.A., Bryden N.A. and Polansky M.M. (1997): Lack of toxicity of chromium chloride and chromium picolinate in rats. J. Am. Nutr. 16(3):273-9.

4. O'Flaherty E.J. (1996): A physiologically-based model of chromium kinetics in the rat. Toxicol. Appl. Pharmacol. 138:54-64.

5. Wahl S.M. (1997): Inflammation and growth factors. J. Urol.157(1):303-5.
6. Sipsas N.V., Sfikakis P.P., Kontos A. and KordossisT. (2002): Levels of Soluble CD40 Ligand (CD154) in Serum Are Increased in Human Immunodeficiency Virus Type 1-Infected Patients and Correlate with CD4+ T-Cell Counts. Clin. Diagn. Lab. Immunol. 9(3): 558-561.

7. Vishnevetsky D., Kiyanista V.A. and Gandhi P.J. (2004): CD40 ligand: a novel target in the fight against cardiovascular disease. Ann. Pharmacother. 38(9):11500-8.

8. Lee A.J., Hodges N.J. and Chipman J.K. (2004): Modified comet assay as a biomarker of sodium dichromate-induced oxidative DNA damage: optimization and reproducibility. Biomarkers. 9 (2):103-15.

9. Lawrence T. (2007): Inflammation and cancer: a failure of resolution? Trends Pharmacol. Sci. 27.

10. Schonbeck U., Varo N., Libby P., Buring J. and Ridker P.M. (2001): Soluble CD40L and Cardiovascular Risk in Women. Circulation. 104:2266.

11. Luke S., Verma R., Conte R. and Mathews T. (1992): Molecular characterization of the secondary constriction region (qh) of human chromosome 9 with pericentric inversion. J. Cell Sci. 103:919-23

12. Anwar W.A. (1991): Cytogenetic monitoring of human populations at risk in Egypt: role of cytogenetic data in cancer risk assessment. Environ. Health Perspect. 96:91-5.

13. Pellerin C. and Booker S.M. (2000): Reflections on hexavalent chromium: health hazards of an industrial heavyweight. Environ. Health Perspect. 108(9):A402-7 
14. Cagnoni F., Oddera S., Michel J.G., Riccio A.M., Olsson S., Dellacasa P., Melioli G., Canonica G.W. and Azzarone B (2004): CD40 on Adult Human Airway Epithelial Cells: Expression and Proinflammatory Effects. J. Immunol. 172: 3205-14.

15. Drillenburg P. and Pals S.T. (2000): Cell adhesion receptors in lymphoma dissemination. Blood 95(6):1900-10.

16. Solis-Heredia M.J., Quintanilla-Vega B. and Sierra-Santoyo A. (2000): Chromium increases pancreatic metallothionein in the rat. Toxicol. 142:111-7.

17. Valko M., Rhodes C.J., Moncol J., Izakovic M. and Mazur M. (2006): Free radicals, metals and antioxidants in oxidative stress-induced cancer. Chem. Biol. Interact. 160(1):1-40. Epub 2006 Jan 23. Links

18. Bigaliev A.B. (1981): Chromosome aberrations in a lymphocyte culture from persons in contact with chromium. Tsitol. Genet. 15(6):63-8.

19. Cohen M.D. and Costa M. (1998): Chromium compounds. In: Rom W.N., editor. Environmental and occupational medicine. Philadelphia: Lippincott-Raven Publishers. p. 1045-52.

20. Powers W.J., Gad S.C., Siino K.M. and Pechman J.C. (1986): Effects of therapeutic agents on chromium-induced acute nephrotoxicity. In: Serrone D.M., editor. Chromium symposium 1986: an update. Pittsburgh (PA): Industrial Health Foundation, Inc. p. 79-86.

21. Zhang G.S. and Jin Y.L. (2006): Studies on the nephrotoxicity of chromium compounds. Wei. Sheng. Yan. Jiu. 35(5):659-62.
22. Dartsch P.C., Hildenbrand S., Kimmel R. and Schmahl F.W. (1998): Investigations on the nephrotoxicity and hepatotoxicity of trivalent and hexavalent chromium compounds. Int. Arch. Occup. Environ. Health. 71 Suppl:S40-5.

23. Agency for Toxic Substances and Disease (ATSDR). (2000): Toxicological profile for Chromium. U.S. Department of Health and Human Services, Public Health Service. Disclaimer Atlanta, GA.

24. Goyer R.A. and Clarkson T.W. (2001): Toxic effects of metals. In, Klaassen C.D., ed. Casarett and Doull's Toxicology: The Basic Science of Poisons, Sixth Edition. Mc-Graw-Hill, New York. p. 811-867.

25. Cocker J., Morton J., Warren N., Wheeler J.P. and Garrod A.N. (2006): Biomonitoring for chromium and arsenic in timber treatment plant workers exposed to CCA wood Preservatives. Ann. Occup. Hyg. 50(5):517-25.

26. Muttamara S. and Leong S.T. (2004): Health implication among occupational exposed workers in a chromium alloy factory, Thailand. J. Environ. Sci. 16(2):181-6.

27. Nordberg M. (1998): Emergency medical dispatch: a changing profession. Emerg. Med. Serv. 27(8):25-6, 28-34.

28. Leroyer C., Dewitte J.D. and Bassanets A. (1998): Occupational asthma due to chromium. Resp. 65:403-5.

29. Barbe-Tuana F.M., Klein D., Ichii H., Berman D.M., Coffey L., Kenyon N..S., Ricordi C. and Pastori R.L. (2006): CD40-CD40 Ligand Interaction Activates Proinflammatory Pathways in Pancreatic Islets. Diabetes 55:2437-45. 
30. Scott D.A., Todd D.H., Coward P.Y., Wilson R.F., Odell E.W., Poston R.N., Matthews J.P. and Palmer R.M. (2000): The acute influence of tobacco smoking on adhesion molecule expression on monocytes and neutrophils and on circulating adhesion molecule levels in vivo. Addict. Biol. 5(2):195-205.

31. Vallejo A.N. (2006): Age-dependent alterations of the T-cell repertoire and functional diversity of T-cells of the aged. Immunol. Res. 36(13):221-8.

32. Aw D., Silva A.B. and Palmer D.B. (2007): Immunosenescence: emerging challenges for an ageing population. Immunol. 120(4):435-46.

33. Hideaki M., Hiroyuki K., Satoru M., Yumiko A., Masafumi T. and Katsuyuki A. (2000): Induction of Chromosomal Aberrations and Growth-Transformation of Lymphoblastoid Cell Lines by Inhibition of Reactive Oxygen SpeciesInduced Apoptosis with Interleukin-6. Lab. Invest. 80:725-734.

34. Housset B. (1994): Free radicals and respiratory pathology. Seances Soc. Biol. Fil. 188(4):321-33.

35. Benova D., Hadjidekova V., Hristova R., Nikolova T., Boulanova M., Georgieva I., Grigorova M., Popov T., Panev T., Georgieva R., Natarajan A.T., Darroudi F. and Nilsson R. (2002): Cytogenetic effects of hexavalent chromium in Bulgarian chromium platers. Mutat. Res. 514(12):29-38.

36. Medeiros M.G., Rodrigus A.S., Batoreu M.C., Laires., Rueff J. and Zhitkovich A. (2003): Elevated levels of DNA-protein cross links and mi- cronuclei in peripheral lymphocytes of tannery workers exposed to trivalent chromium. Mutagenesis 18(1):19-24.

37. Pressl S., Edwards A. and Stephan G. (1999): The influence of age, sex and smoking habits on the background level of fish-detected translocations. Mutat. Res. 442(2):89-95.

38. Milosevic D.C., Grujicic D., Novakovic T., Arsenijevic S. aand Marinkovic D. (2002): Micronuclei and ageing in a sample of Yugoslavian population. Genetika 38(2):264-7.

39. Arboleda M.Y., Hoyos L.S., Carvajal S. and Sierra-Torres C.H. (2004): Genotoxicity from exposure to cigarettes in young smokers in Colombia. Rev. Panam. Salud. Publica. 15(6):36772 .

40. Maeng S.H., Chung H.W, Kim K.J., Lee B.M., Shin Y.C., Kim S.J. andd Yu I.J. (2004): Chromosome aberration and lipid peroxidation in chromium-exposed workers. Biomarkers 9 (6):418-34.

41. Longhese M.P., Mantiero D. and Clerici M. (2006): The cellular response to chromosome breakage. Mol. Microbiol. 60(5):1099-108.

42. Boffetta P., van der Hel O., Norppa H., Fabianova E., Fucic A., Gundy S., Lazutka J., Wasilewska C.A., Puskailerova D., Znaor A., Kelecsenyi Z., Kurtinaitis J., Rachtan J., Forni A., Vermeulen R. and Bonassi S. (2007): Chromosomal aberrations and cancer risk: results of a cohort study from Central Europe. Am. J. Epidemiol. 165(1):36-43. 